\title{
Magnetic resonance imaging of femoral head development in roentgenographically normal patients
}

\author{
Peter J. Littrup, M.D. ${ }^{1}$, Alex M. Aisen, M.D. ${ }^{2}$, Ethan M. Braunstein, M.D. ${ }^{2}$, and William Martel, M.D. ${ }^{2}$ \\ ${ }^{1}$ University of Michigan Medical School and ${ }^{2}$ Department of Radiology, University Hospital, \\ Ann Arbor, Michigan, USA
}

\begin{abstract}
Magnetic resonance images (MRI) of 22 patients with roentgenographically normal hips were reviewed retrospectively and the findings categorized according to age. With increasing maturity, the MR intensity of the femoral heads on spin echo images increased, as marrow fat became a dominant tissue in the head. The femoral head pattern was relatively inhomogeneous, with a broad band of diminished intensity extending in a posteromedial to anterolateral direction, corresponding to the pattern of trabecular bone. The femoral capital epiphyses were visible in younger patients as structures of bright intensity which remained evident through early adulthood. The articular cartilage of the hip joint was noted as a distinctive "halo" around the femoral head. An understanding of the MR pattern of the normal hip will aid in the early recognition of pathologic conditions, such as osteonecrosis.
\end{abstract}

Key words: Magnetic resonance images - Femoral head - Trabecular bone patterns - Articular cartilage - Epiphyses

Magnetic resonance imaging (MRI) of the femoral head has shown promise in the early detection of osteonecrosis [2, 4, 5]. Skeletal MRI offers better definition of medullary bone anatomy and marrow integrity than that seen with plain film radiography. We evaluated medullary bone patterns seen on MRI in patients in different age groups, and compared them with findings on plain radiographs of normal hips in an attempt to establish a baseline for the use of MRI in evaluating early femoral head disease, such as subtle osteonecrosis.

Address reprint requests to: Alex M. Aisen, M.D., Department of Radiology, University Hospital, Ann Arbor, MI 48109, USA

\section{Patients and methods}

Twenty two patients (11 male, 11 female; age range 15 months to 81 years with a mean of 40 years) who underwent MRI examination at the University of Michigan Magnetic Resonance Imaging Laboratory from February-August, 1984 were included in this study. MRI of the pelvis was performed in 20 of the patients for medical reasons other than suspected hip disease, including tumors and other diseases of the pelvic organs. Two patients were scanned for unexplained hip pain. Plain films displaying adequate views of the femoral head and acetabulum were obtained, and only patients with no apparent abnormalities on plain roentgenograms were included in this study. The appearance of the femoral heads on MRI was noted, and the intensity of the MR signal was compared to that of adjacent acetabular bone. The patients were grouped according to age $(0-10,10-20,20-30$, and over 30 years), and the findings were noted for each age group. The intensity and pattern of the femoral epiphyses were also recorded for each patient in which they could be clearly seen. Informed consent was obtained prior to scanning in all cases. Images were also obtained on an excised bovine femoral head using a thin slice $(5 \mathrm{~mm})$ technique.

\section{Imaging techniques}

A Diasonics, Inc. MR imager based on 0.35 Tesla superconducting magnet, using multislice spin-echo data acquisition, was employed for all MR images. Echo-delay times (TE) of 28 and 56 milliseconds (ms) and varying pulse repetition intervals (TR) from $0.5-2.0$ seconds (s) were used. Slice thickness was $7 \mathrm{~mm}$ with a $3 \mathrm{~mm}$ gap between slices and pixel resolution was about $2 \mathrm{~mm}$. Scanning was generally performed in the transverse plane; coronal images were available in eight patients as well.

\section{Results}

The most common MRI pattern of the femoral head in the over 30 year age group was a moderately inhomogenous banded appearance, consisting of a central area of decreased signal intensity as compared to the brighter peripheral zone (Fig. 1). This pattern was primarily seen in the center slice through the head. Variations were often due to apparent differences in slice levels. In all groups, the intensity of the central zone of the femoral 

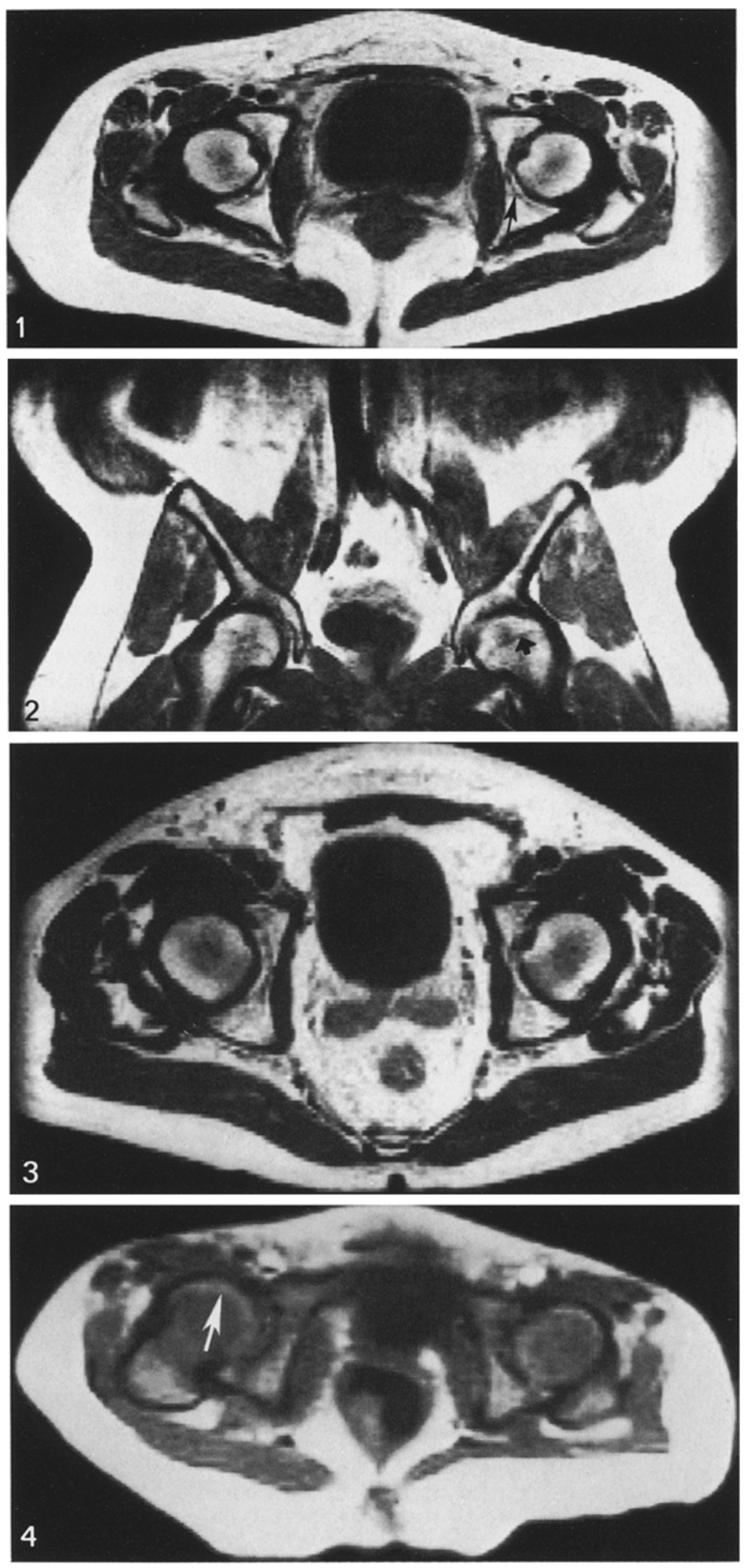

Fig. 1. ${ }^{1}$ Axial MRI $(T R=2.0)$ of a 44-year-old woman displaying the characteristic adult femoral head pattern with a low intensity band coursing posteromedial to anterolateral, corresponding to the trabecular bone pattern. Note the fovea and adjoining ligamentum teres, acetabular fossa fat, and posterior articular cartilage (arrow)

Fig. 2. Coronal MRI (TR $=1.0)$ of a 56-year-old man showing a vertical band of low intensity coursing through the femoral head, comparable to that seen on axial images. Note the thin dark horizontal line in the superior portion of the head, corresponding to the area of physeal closure (arrow)

Fig. 3. Axial MRI (TR $=1.5)$ of a 61-year-old man having the common adult femoral head pattern with widening of the dark central bands, reflecting cumulative trabecular bone formation and decreased marrow fat content

Fig. 4. Axial MRI (TR=0.5) at a level below the ossification center in a 3-year-old girl, showing a homogenous pattern with decreased signal intensity relative to adult patterns (reflecting less marrow fat than in adults). The articular cartilage appears as a bright rim of tissue and in those areas not contiguous to the acetabulum it represents the femoral component of the cartilage (arrow)

\footnotetext{
1 All illustrations in this paper are first echo images, $T E=28 \mathrm{~ms}$, with variable $\mathrm{TR}$ intervals)
} 

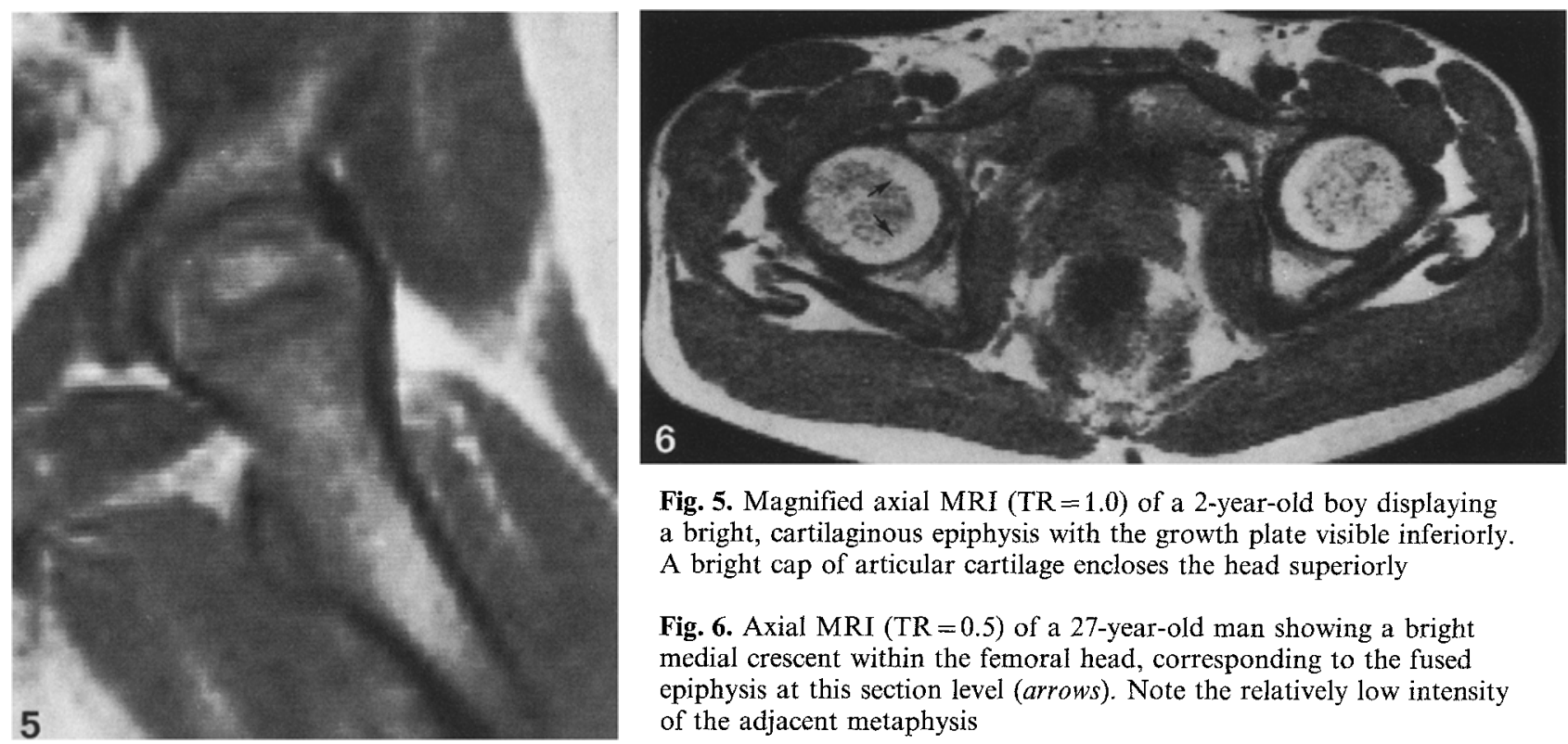

Fig. 5. Magnified axial MRI $(T R=1.0)$ of a 2-year-old boy displaying a bright, cartilaginous epiphysis with the growth plate visible inferiorly. A bright cap of articular cartilage encloses the head superiorly

Fig. 6. Axial MRI (TR =0.5) of a 27-year-old man showing a bright medial crescent within the femoral head, corresponding to the fused epiphysis at this section level (arrows). Note the relatively low intensity of the adjacent metaphysis
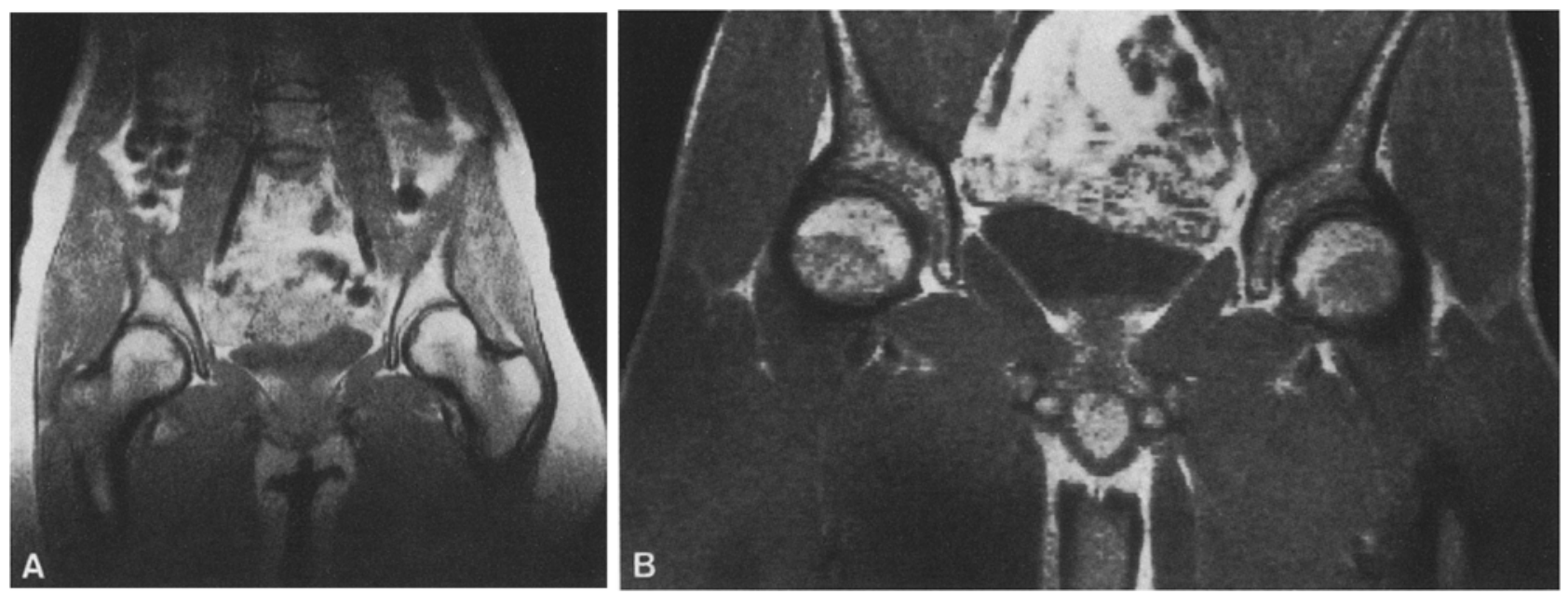

Fig. 7. A Coronal MRI (TR = 1.0) of a 15-year-old girl displaying bright femoral capital and greater trochanteric epiphyses which appeared fused on plain films. B Coronal MRI $(\mathrm{TR}=1.0)$ of a 24-year-old man also having bright capital epiphyses with a striking linear trabecular bone pattern beneath it. Note fine rim of femoral articular cartilage and acetabular fossa fat in both hips

head was comparable to the overall intensity of the adjacent acetabulum. On transaxial images, a low intensity band coursing posteromedial to anterolateral through the femoral head was consistently present (Fig. 1). A similar, corresponding band was seen on coronal images coursing vertically through the femoral head (Fig. 2). These bands appeared in the 20 to 30 -year-old group and continued throughout life. After 60 years of age, the overall intensity of the head decreased as the diameter of the low intensity bands gradually increased (Fig. 3).

In the pediatric age range ( $0-10$ years), the femoral head appeared more homogenous and less intense than the adult pattern (Fig. 4). The femoral capital epiphysis was best seen on coronal MRI as a separate high intensity structure located superior-medial to the femoral head (Fig. 5). The inconsistent appearance of the epiphysis on transaxjal images depended upon the slice level through the femoral head and was commonly seen as a bright medial crescent (Fig. 6). As the patients entered the adolescent range (10-20 years), the space between the epiphysis and metaphysis gradually narrowed until the physis fused. At this point, the epiphysis was still of far greater intensity than the juxtaposed metaphysis (Figs. 6, 7 A, B). As age increased, the intensity of the metaphysis gradually increased while the femoral head began to develop the inhomogenous banded appearance of adults. 


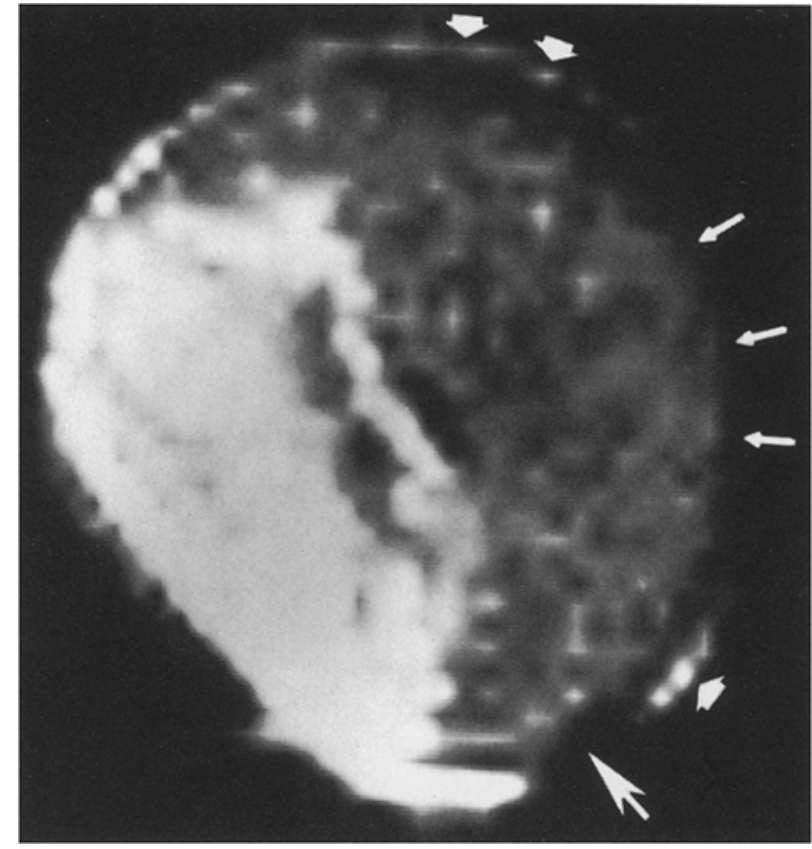

Fig. 8. Magnified thin-slice $(5 \mathrm{~mm})$ slice image of an excised bovine femoral head, showing the cartilage as a thin, white line (wide arrows) with a naturally denuded region of bone (small arrows) and an area of cartilage scraped off with a knife (large arrow). $(\mathrm{TR}=0.5 \mathrm{~s} ; \mathrm{TE}=28 \mathrm{~ms})$
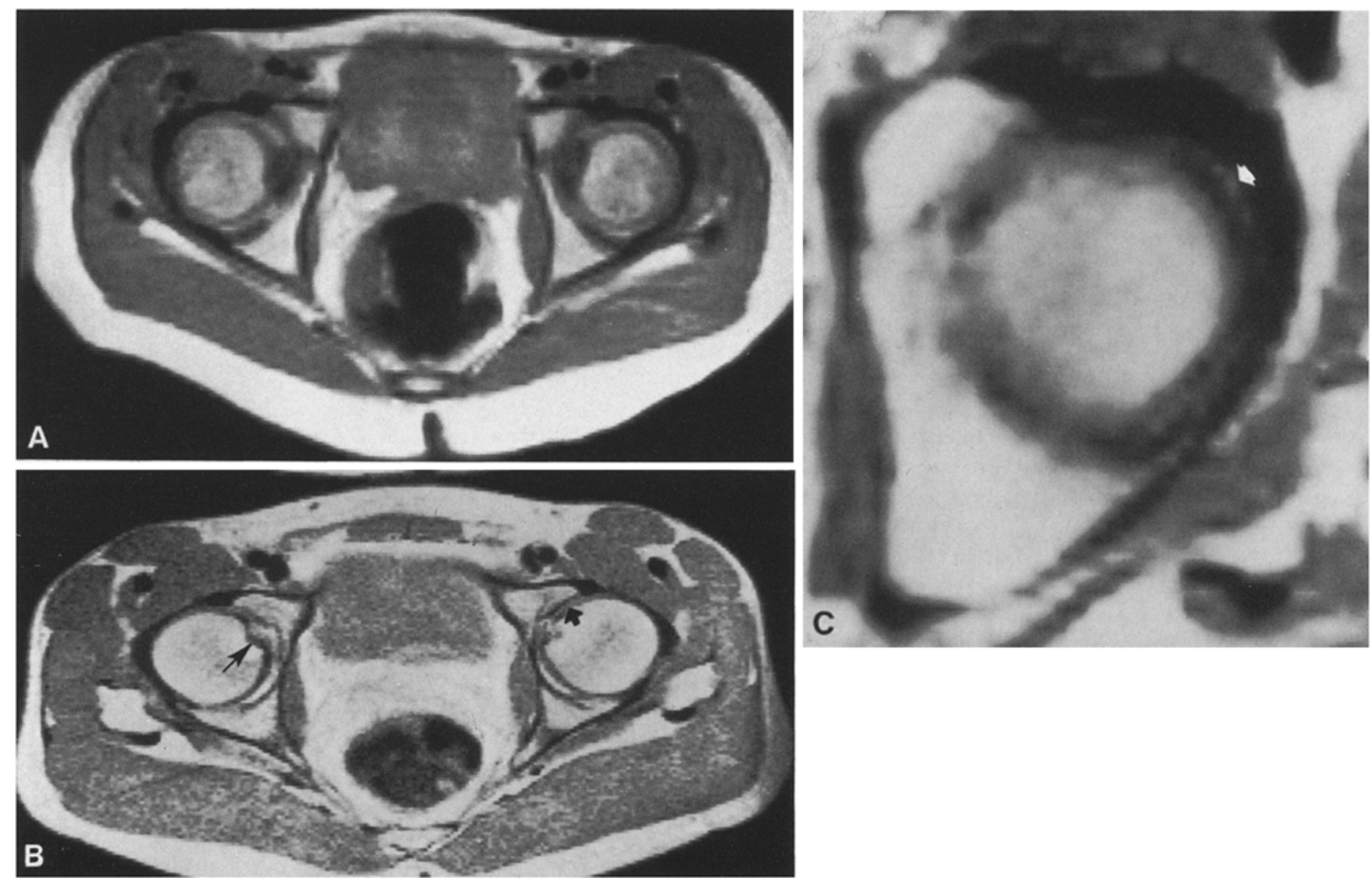

Fig. 9. A Axial MRI (TR=2.0) of a 6-year-old girl showing prominent bright "halos" about the femoral heads. The remarkable continuity of the cartilage bilaterally is due to sectioning serendipity. Note also the relative homogeneity and absence of the dark central band. The fovea in each hip has a low intensity, presumably because the section includes more ligamentous than fatty tissue. B Axial MRI (TR $=2.0$ ) of a 27 -year-old man having a thin discontinuous rim of articular cartilage extending laterally over the femoral head (wide arrow). Note also the fovea, ligamentum teres, acetabular fossa fat (irregularly shaped at the fovea and extending posteriorly) (long arrow) and posterior cartilage. C Magnified axial MRI (TR $=1.5$ ) of a 61-year-old man revealing only a faint segment of articular cartilage contiguous to the femoral head (arrow) 
Table 1. Summary of MRI findings

\begin{tabular}{|c|c|c|c|c|}
\hline $\begin{array}{l}\text { Age } \\
\text { (years) }\end{array}$ & $\begin{array}{l}\text { Physeal } \\
\text { epiphysis }\end{array}$ & $\begin{array}{l}\text { Growth } \\
\text { plate }\end{array}$ & Metaphysis & $\begin{array}{l}\text { Articular } \\
\text { cartilage }\end{array}$ \\
\hline $0-10$ & $\begin{array}{l}\text { High } \\
\text { intensity } \\
\text { region }\end{array}$ & $\begin{array}{l}\text { Low } \\
\text { intensity } \\
\text { band }\end{array}$ & $\begin{array}{l}\text { Low intensity } \\
\text { homogeneous } \\
\text { region }\end{array}$ & $\begin{array}{l}\text { Bright } \\
\text { crescentic } \\
\text { line }\end{array}$ \\
\hline $10-20$ & $\begin{array}{l}\text { High } \\
\text { intensity } \\
\text { region } \\
\text { becoming } \\
\text { absent }\end{array}$ & $\begin{array}{l}\text { Narrowing } \\
\text { low } \\
\text { intensity } \\
\text { band }\end{array}$ & $\begin{array}{l}\text { Increasing } \\
\text { intensity; } \\
\text { developing } \\
\text { low intensity } \\
\text { central bands }\end{array}$ & $\begin{array}{l}\text { Bright } \\
\text { crescentic } \\
\text { line }\end{array}$ \\
\hline $20-30$ & Absent & $\begin{array}{l}\text { Thin, } \\
\text { residual } \\
\text { low } \\
\text { intensity } \\
\text { line }\end{array}$ & $\begin{array}{l}\text { High intensity } \\
\text { with low } \\
\text { intensity } \\
\text { central bands }\end{array}$ & $\begin{array}{l}\text { Bright } \\
\text { crescentic } \\
\text { line }\end{array}$ \\
\hline$>30$ & Absent & $\begin{array}{l}\text { Thin, } \\
\text { residual } \\
\text { low } \\
\text { intensity } \\
\text { line }\end{array}$ & $\begin{array}{l}\text { Widening of } \\
\text { central low } \\
\text { intensity } \\
\text { bands }\end{array}$ & $\begin{array}{l}\text { Bright } \\
\text { crescentic } \\
\text { line, } \\
\text { becoming } \\
\text { thinner } \\
\text { with } \\
\text { increasing } \\
\text { age }\end{array}$ \\
\hline
\end{tabular}

A residual line of low intensity, corresponding to the area of physeal closure, could be found on coronal images in appropriate slices (Fig. 2).

A halo of intermediate signal intensity surrounding the femoral head and noted in 14 patients, was felt to be articular cartilage or its gelatinous surface. Within the hip, this zone of intermediate signal probably represents both femoral and acetabular cartilage, and a variable amount of fat. We were able to identify femoral articular cartilage as a distinct structure in peripheral areas where it was not within the acetabulum proper. The ability to identify femoral head cartilage was verified by imaging an excised bovine femoral head (Fig. 8). The joint cartilage was a prominent structure in children and adolescents and became thinner in adults (Fig. 9A-C). However, joint cartilages could be seen clearly on selected images in the adult category (Figs. 1, 7B, 9B and 9C). The fovea and ligament of the femoral head as well as the high intensity fat of the acetabular fossae could also be distinguished on specific center slices (Figs. 1 and 9B). Bilateral comparison of the hip joints was best done on the coronal images as the transaxial views were often hampered by variable cranial-caudad position of the joints. These findings are summarized in Table 1.

\section{Discussion}

Comparison of MRI with normal plain radiographs has allowed us to assess the growth and development of the hip joint as well as the integrity of the femoral head and cartilage. Trabecular bone pattern appears to be a function of the patient's age and must be considered in the evaluation. The epiphyses were seen consistently as high intensity structures probably due to the high water content [3] of their cartilaginous composition. Secondary endochondral ossification appears to continue in adolescents after epiphyseal fusion is complete as judged on plain film radiographs (Figs. 6 and 7A, B). The development of a banded pattern in the femoral head during the third decade corroborates previous findings $[4,5]$ and corresponds to the "asterisk sign" [1] on computed tomography. The variety of patterns seen in our study can be accounted for by the individual differences in trabecular bone development. Major mechanical stress vectors of the femoral head are reflected by a vertical band on coronal MRI and a posteromedial to anterolateral band on transaxial MRI (Figs. 1 and 3). These bands were found to increase in width in the geriatric group (over 60 years); this probably represents the cumulative effects of mechanical stress on the femoral head.

The articular cartilage appears as a bright halo perhaps due to its high water content [3] and resultant short T1. The bony cortex is not seen on MRI, such that the articular cartilages appear separated from the femoral head and subjacent to acetabular cortex. This appearance has been noted previously $[2,5]$. Our ability to detect thinning of this structure with age, using MRI, suggests that this modality may be of value in detecting alterations of articular cartilage preoperatively. The normal anatomy of the hip at various ages can be clearly defined by MRI. Knowledge of this anatomy is essential for the proper assessment of diseases of this joint.

\section{References}

1. Dihlmann W (1982) CT analysis of the upper end of the femur: The asterisk sign and ischaemic bone necrosis of the femoral head. Skeletal Radiol 8:251

2. Genant HK, Richardson ML, Heller M, Helms CA, Chafetz NI (1984) Magnetic resonance imaging of the musculoskeletal system. In: Scientific Program of the Society of Magnetic Resonance in Medicine, Third Annual Meeting, August 13-17, 1984, New York, New York Society of Magnetic Resonance in Medicine, Boston, Mass, p 259

3. Jaffe HL (1972) Metabolic, degenerative and inflammatory diseases of bones and joints, 1 st edn. Lea and Febinger, Philadelphia, $\mathrm{p} 15$

4. Moon KL Jr, Genant HK, Helms CA, Chafetz NI, Crooks LE, Kaufman L (1983) Musculoskeletal applications of nuclear magnetic resonance. Radiology 147:161

5. Totty WG, Murphy WA, Ganz WI, Kumar B, Daum WJ, Siegel BA (1984) Magnetic resonance imaging of the normal and ischemic femoral head. AJR 143:1273 